\title{
THE EFFECT OF INTEGRATION ON LEARNING: AN ANALYSIS AND EVALUATION OF A LEGAL WRITING PROJECT IN A SOUTH AFRICAN LAW FACULTY
}

Toni Gottlieb \& Lesley Anne Greenbaum

University of Cape Town

This article analyses the implementation and evaluation of a first-year legal writing programme which, over a period of three years, was increasingly integrated into the law curriculum of two first-year courses with a concomitant improvement in students' assignment marks, as well as in their and their tutors' perceptions of their learning. It argues that an increasingly integrated approach improves the legal reasoning and writing abilities expected of a first-year law student. The course design focused on the genres required in the law degree along with the underlying cognitive skills of analysis, synthesis, application, evaluation and argument necessary for legal reasoning. Students were required to submit four writing tasks to trained final-year student writing tutors who provided extensive personalised feedback. These ungraded tasks served to scaffold students' subsequent submissions of coursework assignments. External evaluations of the project each year facilitated reflection and informed changes made to the project design. The conclusion drawn is that a particular type of integration that is achieved through 'insider-outsider' collaboration between an academic literacy expert and a law academic may be most effective in achieving the desired outcomes.

\section{INTRODUCTION}

In 2014, the Department of Higher Education and Training awarded a Teaching Development Grant to the Law Faculty of the University of Cape Town (UCT) to implement a legal writing project for first-year law students. The grant came in the wake of complaints from law practitioners and academics about the poor literacy skills of law graduates (Bangeni \& Greenbaum, 2013; Snyman-van Deventer \& Swanepoel, 2013.) The focus of the innovative Legal Writing Project (LWP) was to integrate the teaching of legal literacy skills into the disciplinary content of two first year law courses: Foundations of South African Law and the Law of Persons and Family.

Beginning with the background to the project, the paper describes the theoretical approaches that informed the design of the LWP, followed by a description of the project curriculum. The purpose is to determine which of these approaches and which changes made to the project over the three years might have contributed to the significant improvement in the students' grades for their law assignments and to their more positive evaluation of the LWP. The conclusion drawn from the findings is that the increased integration of legal-literacy development into the disciplinary content of law, as well as the cumulative emphasis on critical thinking, might have been two factors that enhanced the positive outcomes of the project. This conclusion is confirmed by the external evaluation of the project. 


\section{BACKGROUND TO THE LEGAL WRITING PROJECT}

The project was structured around the legal-literacy requirements of two subject courses, and focused on explicating the skills required in the course assignments: a case summary, a case note, a problem essay and an argumentative essay. The lectures were scheduled around the due dates of the assignments, providing sufficient time to explicate the skills, practise the genre on a low-stakes writing task, and receive personalised written feedback from trained writing tutors.

The LWP had two primary aims: to develop students' critical thinking, reading, reasoning and writing practices, which are fundamental to law, by explicating the subsidiary skills of analysis, synthesis, application, evaluation and argument; and to reveal the connections between these skills and their roles in the process of meaning-making in law through their practical application in writing tasks.

As Rideout and Ramsfield (1994: 55) point out, legal writing is not just the translation of a legal analysis but the analysis itself: 'The act of writing is intimately involved with the act of construing the law - describing and synthesising the applicable law, applying legal rules, drawing analogies and distinguishing facts, and developing legal arguments.'

\section{THEORETICAL APPROACHES}

\section{New Literacy Studies: Literacy as a social practice}

The central tenet of New Literacy Studies (NLS), that language and literacy are social and ideological constructs and dependent on their context of use, shaped the design of the project. This view informs a number of theories that align themselves with NLS by challenging what Street $(1984: 28 ; 2003)$ calls the 'autonomous' model of literacy as a neutral, discrete set of cognitive skills that enable an individual to encode and decode texts.

Rather, drawing on Street's 'ideological' model, these theories view literacy as situated social practices - contextual, task-related and embedded in discourse and ideology. Literacy is therefore always plural - 'literacies' - and unless we understand literacy not as 'a matter of individual choice or proclivity, but of learning and reading practices of an interpretive community' (Wickert \& Baynham, 1994: 157), and unless we consider the influences of a discipline's practices on reading and writing, and develop an awareness of 'the functions of texts and how these functions are conventionally accomplished' (Hyland, 2000: 393), we can have only limited understanding of literacy practices and texts (Wickert \& Baynham, 1994).

Candlin, Bhatia and Jensen (2002) explain the common difficulty in transferring knowledge of one disciplinary literacy to another. Language and content in law, they say, are 'more intimately integrated':

Law, after all, does not exist naturally in its own state; it is constructed, interpreted, and negotiated through language. Legal concepts and the knowledge that expresses them form a dense, precisely interwoven texture which blurs the distinction between language and content (Candlin, Bhatia \& Jensen, 2002: 313).

One of the main criticisms of the autonomous model of literacy is that it promotes a deficit notion of literacy, attributing blame to the individual, whether teacher or learner, if the skills of reading and writing have not been acquired. In contrast to the autonomous model's fixation on teaching methods, new technologies and standards of education, the social account is interested 
in how one's cultural and linguistic experiences in the home and the community influence the process of achieving academic literacy (Barton \& Hamilton, 1998: 21). It is this concept of specific literacy practices among particular communities of practice that informed the teaching of legal writing to first-year law students. The view of literacy as a social practice was fundamental to the design of the LWP.

\section{Genre approach: Explicit teaching and use of samples}

Competence in the highly ranked and highly conventionalised genres of the legal profession opens access to the world of law. The overriding aim of the teaching, therefore, was to empower students with the structural, analytical and linguistic tools for reading and writing academic and legal texts. While this suggests a predominantly formalistic focus, an important component of this process involves critical awareness of the specific social context of the text. At the outset, thus, each text was situated in the context of its purpose, the situation that precipitated it, and its intended reader - in other words, why it was written and what it is trying to achieve. As Kress (1993: 27) says, 'it is the text in its full social and cultural context which provides the relevant starting point for any useful speculation about the forms, uses and functions of its language.'

The conventionalised forms of legal writing are well-suited to the genre approach with its pedagogic stages of modelling, joint negotiation and independent construction of a text. The genre approach espouses explicit formulation of the structural, linguistic and discursive strategies that are conventionally deployed to achieve a particular communicative purpose in a specific social context (Bhatia, 1993; Callaghan \& Rotheray, 1998). This explicit pedagogy is a reaction to the traditionally tacit communication of lecturers who assume students' implicit understanding of academic and legal writing, or expect them to acquire it by osmosis (Greenbaum, 2004: 7). As a result, access to these textual forms of power is provided to those who have already been granted it through their historic enculturation in their conventions. In line with the genre approach, the LWP systematically scaffolded first-year law students in the literacy processes of reading and writing by explicating the ways in which the textual patterns, both in content and form, are constructed, while simultaneously evaluating authoritative legal and academic texts through a critical awareness of their purpose, meaning and effect.

\section{Multiliteracies: Expanded notion of text}

The pedagogy of multiliteracies, espoused by the New London Group (1996), expands on the 'situated practice' of the social approach of the NLS and the 'overt instruction' of genre theory's principle of access for success by including two additional components. The first of these is 'critical framing', which surfaces the unspoken assumptions of a text and evaluates its articulated meaning. The second is 'transformed practice', through which students transfer meaning from one context to another (New London Group, 1996).

A key feature of multiliteracies is its expanded notion of text to include other modalities such as visual, aural and physical. The LWP incorporated visual text such as videos, pictures, diagrams, charts, and labelled and annotated samples to explain the complex structures of deductive and inductive reasoning, rule synthesis, and application of the law to the facts, which are used in legal argument. These higher-order thinking skills were then transferred to the legal contexts of case analysis, case summary, problem solving and legal reasoning (Venter, 2006: 633). Central to each of these processes was critical thinking: the ability to stand back and reflect on the discursive practices that produce these legal genres, and to evaluate their veracity. 


\section{Academic literacies}

The pedagogy of academic literacies, espoused by Lea and Street (1998; 2006), further expands on the socially situated methods that informed the teaching, by including the importance of 'active learning'. Students ought to be involved as active participants in their own learning. Hyland (2000: 36-37) eloquently sums this up:

The goal then, is for learners to acquire the skills needed to create their own meanings using the socially recognized discursive practices drawn on by full community members. This involves developing a generative capacity rather than an adherence to rules, an exploitation of forms rather than a compliance to them. ... In these ways students might come to understand the conventions of their [disciplinary] communities and more readily view these conventions as possibilities rather than constraints.

This imperative formed the basis of the LWP, which included exercises and written tasks that required critical thinking and independent learning for every genre taught.

\section{APPLICATION TO THE LEGAL WRITING PROGRAMME}

The focus of the LWP was to explicate the skills required by three Foundations of South African Law assignments and one Law of Persons and Family assignment: a case summary, a case note, a problem essay and an argumentative essay. Ramsfield and Rideout (1994: 85) stress the importance of exploring more than one genre in the first year, as they introduce 'differences in rhetorical considerations of audience, purpose, scope and ethos.'

There was conscious continuity among the lecture topics themselves, as well as between the topics and the substantive-law course assignments. While it was challenging to encourage the participation of 270 reticent first years through questions and exercises during an interactive lecture, the four in-class writing tasks ensured learner-centred, active learning. Each of the tasks, which was explained and scaffolded during a lecture, was intended to prepare the students for the impending assignment.

\section{Topics}

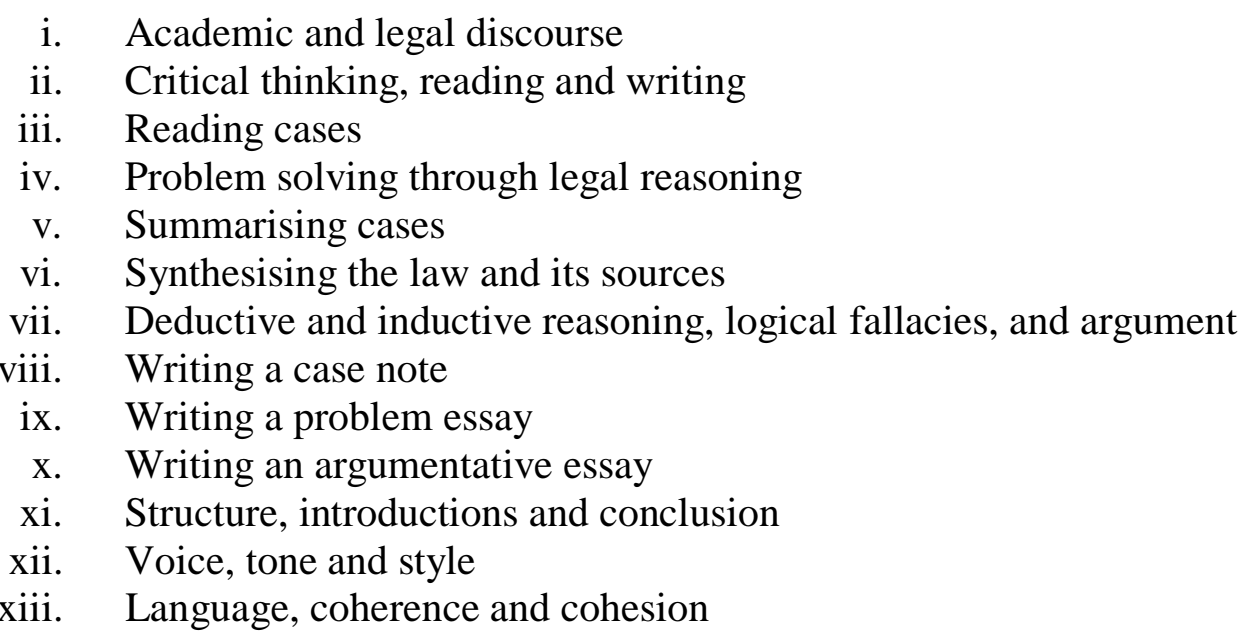

The topics reflected the subsidiary skills underlying each of the assignment genres and incorporated the higher-order critical-thinking skills of analysis, synthesis, evaluation, application and argument, which are fundamental to academic and legal discourse (Venter, Per Linguam 2018 34(1):47-59 
2006). Reading cases formed the basis of these skills and required modelling the critical reading processes used by expert legal readers (Lundeberg, 1987; Oates, 2006).

In the first two years, a dedicated class on language, specifically dealing with linking devices and transitions, addressed the language needs identified in students' written assignments. In the third year, at the suggestion of the students and the realisation that the language class added little value, language was incorporated into the other classes.

Ten of the 14 classes included discussions, worksheets, and analysing two strong and two weak student writing samples. The four samples were selected to reveal the different ways an assignment can achieve a high or low mark. This was to avoid displaying a 'model' that would prescribe a formula for writing and which students would try to emulate. Two of the samples were first analysed to demonstrate what made them strong or weak. The students then analysed the other two in pairs or small groups, and reported their findings to the class. It was important that students understood that good writing can never be formulaic, despite the rigorous conventions, style and tone of the legal genres they were learning.

\section{Assignments}

External evaluations were conducted annually, which facilitated reflection and adaptation. One of the changes to the design of the classes was the introduction of past assignment questions to illustrate the various skills. This resulted in far more integration into the discipline-specific content of the law subjects. In the third year, the assessment criteria and marking memos from the previous year's assignments were included. Each lecturer's choice of assignment mirrored the texts the students would write in legal practice: case summary, journal-article case note, memorandum of opinion and research memo respectively. Students thus had the opportunity to transfer meaning from one context to another. Scaffolding the assignments meant explicating the underlying legal methods and literacy skills required for each. The critical thinking skills of analysis, synthesis, evaluation, application and argument were unpacked step by step.

There were two significant outcomes concomitant with the increased integration. The first was that students' evaluations of the LWP were increasingly more positive, particularly regarding the literacy skills required for these legal genres. The second was that students' marks for all four assignments increased significantly from 2014 to 2015 . The causal relationship is uncertain but there was undoubtedly an increase in ability to tackle the assignment questions.

\section{Case summary}

A case summary is more than simply a précis. Selecting the necessary information requires students to uncover the case's idiosyncratic components, most of which are not signposted. In particular, students must 'spot' the issue - the precise legal question on which the case turns, as distinct from the factual problem that brought the case to court - and formulate it in a singlesentence interrogative. Students learn that formulating the often-elusive issue is facilitated by first finding the ratio decidendi, the legal principle on which the judge relied to answer the issue and ultimately reach a decision. The judge's reasoning, which constitutes the bulk of the case, involves applying the relevant legal rules or principles to the facts of the case and using logical reasoning to justify her final decision based on the ratio decidendi. The facts of the case are themselves not easy to select for inclusion in the summary, as it is only the legally-relevant facts that must be included, and the relevance of a fact is contingent on the issue, which is in 
turn determined by the facts. While the components of a case are named by the lecturers, students are rarely shown how to distil the different parts.

\section{Case note}

The second assignment was a case note, which required students to critique the reasoning and decision of a judgment - a difficult task for first-years who are still struggling to find their academic and legal voices, and have yet to gain the confidence to question a judge's authority.

The focus of a case note is its critique, but an initial brief summary of the case is required to contextualise the writer's argument. The significant $10 \%$ increase from 50\% in the 2014 average grade to $60 \%$ in 2015 could possibly be attributed to the scaffolding of the assignment instruction in 2015 but not in 2014. This was even more rigorously scaffolded in 2016, with a concomitant $10 \%$ increase in the mark average to $70 \%$. Causality is always difficult to prove in a pedagogical intervention, and there are mitigating factors such as a change in the subject tutors who marked the assignment in 2014 and 2015. Nevertheless, the same subject tutors marked the 2015 and 2016 assignments. The second mitigating factor is the assignment of different cases to critique from one year to the next, with a degree of possibly more or less difficulty.

\section{Problem-solving essay}

The third assignment was the problem-solving essay - the precursor to legal opinions including judgments. Legal reasoning involves applying the elements of law to the relevant facts and using this, as well as logic, to justify the conclusion reached. There are contingent steps, however, that are rarely made explicit. Before one can apply the law, one needs to analogise and distinguish cases, and synthesise a rule of law from the various principles of law extracted from the other cases. Only then can one apply the synthesised rule to the facts of the given case to draw a conclusion as to what the judge's decision might be.

The genre of the judgment is distinguishable by its characteristic language. While explicit teaching is necessary to acquire the language and literacy tools, a concomitant aim was to explain the discursive reasons for and the social effects of their use, to reveal the strategic devices that underlie the apparent common sense of its features; as Bhatia (1993:182) says, to 'offer genre-specific explanation as to why certain features of language realise specific values in individual genres.'

Legal reasoning uses deductive reasoning when it applies a rule of law to the facts to draw a conclusion. If the rule derives from legislation and needs no interpretation, its application is straightforward and the conclusion certain. When, however, a rule needs to be interpreted, or sometimes even expanded to fit a particular set of facts, a judge will turn to case law using inductive reasoning to synthesise legal principles into an applicable rule of law that is only then applied to the facts. The outcome of this process and the judge's final decision, which results from the application of this rule, cannot be unequivocal or necessarily true. The number of cases that go on appeal to a higher court attests to this.

\section{Argumentative essay}

The fourth assignment that was scaffolded in the LWP was an argumentative essay. In the Law faculty, about a third of the 270 first-year class had had no experience of academic discourse the need to join the academic conversation, take a position, formulate a claim and justify it with evidence. Another third had had only one year of experience at tertiary level in a different 
faculty and no necessary experience of academic essay writing. The remaining third were graduates from disciplines other than law.

After consolidating the features of an argument, using labelled samples to illustrate the moves, the students evaluated a strong and weak essay and identified the features, or lack thereof, that determined the mark. Once they had identified a claim, sub-claims, justification (both authorial and logical evidence) and smooth integration of sources, a focus was placed on structure: introductions, conclusions, paragraphs and coherence.

Introductions

An analysis of the introductions of several strong student essays, as well as of two excellent and accessible journal articles, revealed the inclusion of all the following features: a brief contextualisation of the essay; the question or issue; the writer's viewpoint or answer to the question, i.e., the claim expressed in the form of a thesis statement; and the arguments that would be presented in support of the claim, forming a roadmap of what the reader could expect.

\section{Conclusions}

In the final paragraph or section, after briefly summarising the arguments, it was evident that writers of good essays or articles consistently draw conclusions from the findings of each argument, which support and reiterate the claim made in the introduction.

\section{Paragraphs}

Analysing the paragraphs in the sample texts provided an opportunity to point out coherence or 'flow' in texts. The strong samples tended to use deductive order, starting with the general in the form of topic sentences, which stated the subject of the paragraph, and moving to specific instances in the form of supporting sentences that expanded on the topic sentence. While avoiding a prescriptive approach, it was apparent that, in legal writing, deductive order is followed in the application of a general rule to specific facts to reach a conclusion, and in academic writing this format increases clarity. The reader wants to know at the outset what to expect.

\section{Coherence}

Transitions and linking devices that achieved coherence or 'flow' within and between paragraphs were identified. This led to an explication of grammatical structures such as coordinators (e.g. and, but, so), subordinators (e.g. if, because, after), relative pronouns (who, which, that) and transitions (e.g. however, moreover, therefore), as well as the attendant punctuation. 


\section{WRITING TASKS}

Peter Elbow's (1997) concept of developmental 'low-stakes' writing informed the function and form of the four writing tasks the students wrote in preparation for the 'high-stakes', graded assignments of their law courses. 'The goal of low stakes assignments is not so much to produce excellent pieces of writing as to get students to think, learn, and understand more of the course material' (Elbow, 1997: 5). Because students are not anxious about a grade, they are more inclined to engage with the task of reading and writing for meaning (Louw \& Broodryk, 2016).

The tasks, which were past assignments or exam questions, mirrored the impending assignments, the main difference being that the tasks were ungraded. Instead, extensive written feedback was provided by writing tutors appointed and trained specifically for that purpose.

\section{TRAINING OF WRITING TUTORS TO PROVIDE FEEDBACK}

A number of writers (Bloom, 2008; Elbow, 1997; LeClercq, 1999) have expounded on the importance of formative assessment for developmental purposes, as opposed to assessment for gatekeeping purposes. Therefore, feedback, as opposed to grades, is an important part of this process and formed the backbone of the LWP.

Eight legal-writing tutors were selected from applicants who were final year LLB students. Part of their training included an intensive all-day workshop on the principles of effective feedback along the lines suggested by Bloom (2008) and Elbow (1997). Topics covered included a hierarchy of responses in order of importance, which depended on the student's needs, beginning with a well-justified argument, then focusing on structure and coherence, followed by appropriate tone and style and, only if these had been accomplished, looking at language. The importance of commenting on what was done well, not only what was done poorly, was emphasised, both to encourage students so they would not lose confidence, give up or resist the suggestions, and to ensure they understood what to keep doing and what to change.

The exercises at the training workshop required the tutors to respond in writing to a strong and a weak answer to past assignments on the case summary, the case note, the problem essay and the argumentative essay.

In addition to the workshop, a meeting was held before each writing task, which aimed at aligning the feedback with the assessment criteria for the task. Further scaffolding of the tutors, to ensure they were responding appropriately, was provided when their individual feedback on three samples was moderated.

\section{CHALLENGES}

\section{English as the medium of instruction}

While $86 \%$ of the students who responded to the evaluation survey in 2014 regarded English as their first language, this decreased to $78 \%$ in 2015 and $64 \%$ in 2016 . This may reflect the shift in the profile of all first law students, following the new UCT admission policy in 2016 and the incremental realisation of demographic targets. Thus, for a significant number of students, English is a second or third language. However, as Gee (1991) maintains, language can be acquired only in the context of its use. Students immersed in reading and writing for the discipline will therefore acquire the language along the way. 


\section{Embeddedness}

Clarence, Albertus and Mwambene (2014) describe a legal-writing initiative at another Law faculty, in which an academic literacies (AL) specialist and subject lecturers collaborated on its design and implementation. Candlin et al. (2000: 314) agree that discipline specialists and AL specialists should co-teach or, at the very least, collaborate. In their experience, AL teachers do not have legal backgrounds and might be seen by discipline specialists as intruding on the latter's territory. Jacobs (2005) argues convincingly for the benefits of collaboration using Gee's concept of 'insider' and 'outsider' to a discourse community, and his distinction between tacit 'teaching-for-acquisition' through a demonstration of discipline mastery and explicit 'teaching-for-learning' through developing meta-knowledge.

Whereas Gee (1996) argues that discipline specialists should articulate their tacit knowledge and teach it explicitly, Jacobs (2005) prefers a discursive exchange between the discipline specialist, who is immersed in the discourse, and the AL specialist, who has an objective vantage point outside it, to fuse the two types of teaching without compromising either. Jacobs terms this 'insider-outsider collaboration' - the collaboration between the academic development practitioner, who is outside the discourse and thus more aware of its metalanguage, and the lecturer, who is entrenched in the discourse of the discipline and thus less likely to articulate its workings (Jacobs, 2005). Ideally, this type of pedagogic partnership would address concerns of how best to effectively embed and integrate the exposition of legal literacy practices within the discipline content.

\section{Lecturers' attitudes to teaching legal writing}

A content-heavy law curriculum and the perceived higher status of doctrinal courses contribute to the view of many South African law academics that writing skills should be taught in firstyear introductory courses or practical-skills courses only. Many lecturers resist the notion of teaching writing and legal literacy on the basis that they are not language experts. Some law academics believe that writing cannot be taught; that students should have mastered writing by the time they enter university or acquire legal writing skills by osmosis, immersing themselves in discipline content (Greenbaum, 2004: 10).

Gee's insight into the significance of one's primary discourse (ways of thinking, seeing, being and communicating that are acquired in the home) for the acquisition of a secondary discourse (one acquired later in life in communities outside the home, e.g., school, religion, university, work) exposes the injustices of a 'sink-or-swim attitude' (Gee, 1991). Gee theorises that, the closer the alignment between one's primary discourse and a secondary discourse, the easier it is to learn the new discourse. By assuming knowledge of specific ways of thinking and communicating, which may or may not be aligned to students' primary discourses, lecturers privilege some students. In so doing, they perpetuate unequal access to powerful secondary discourses (Gee, 1996).

\section{Large classes}

The importance of writing and discussion to construct meaning, to formulate one's thoughts, to engage in critical thinking, and to apply and practice the learning cannot be overstated. While the intention was to facilitate this process through class exercises, discussions and writing tasks, the rows of seats in a lecture hall large enough to accommodate 270 students were not conducive to an interactive process. Small tutorials or workshops would have facilitated this better, but 
the available resources (funding, venues, time and staff) were insufficient.

\section{COURSE EVALUATION}

Part of the DHET grant was allocated to an external evaluation of the LWP. The results of the evaluation informed the design and implementation of the LWP in successive years. In the final class of each year, roughly half the registered first-year law students completed a survey questionnaire. Ethical clearance was obtained for the use of the data from the evaluations.

In addition, the writing tutors from each year completed their own questionnaire, which included their perceptions of the value of the LWP and its topics, as well as their own perceptions of students' improvement and the contribution of the LWP to their learning. The writing tutors were also required to evaluate their own development in their ability to give constructive feedback, and in their deeper understanding of legal literacy as a result of their training, their exposure to the explication of legal writing skills and their experience of giving feedback.

\section{Results of the evaluation}

\section{Students}

The students' evaluations were interesting in that, in each successive year, they were increasingly positive. This accorded with the significant improvement in assignment grades. The reasons for this can only be speculative as causality is always difficult to establish, but a number of propositions that relate to the changes in the project from one year to the next emerge.

i. The primary proposition is the increased integration into the disciplinary content. In each successive year, the LWP was more deeply embedded in the Foundations of South African Law and Law of Persons and Family substantive courses through the increased use of prescribed texts, such as legislation and cases, for exercises and tasks, and of past assignment and exam questions to scaffold the various legal genres. In addition, the assessment criteria of each assignment were systematically unpacked.

ii. A second proposition is the more rigorous explication and application of criticalthinking, -reading and -writing skills to interrogate and evaluate texts, even highly authoritative and powerful ones such as court judgments. The feedback from writing tutors and students alike was extremely positive, and the students' answers to the exercise questions provided valuable insight into areas where they needed additional support on this aspect of academic and legal discourse.

iii. A third proposition inheres in the closer alignment of the feedback on the preparatory tasks with the law-assignment assessment criteria. This was achieved in three ways: firstly, by combining the assessment-training workshop for the subject tutors, who marked the assignments, with the feedback-training workshop for the writing tutors, who gave feedback on the ungraded writing tasks; secondly, by including the subject tutors in all the preparatory meetings before the writing tutors gave feedback on the tasks; and thirdly, by going through the marking memorandum in these meetings. 


\section{Writing tutors}

The legal writing tutors were consistently positive in their responses, mentioning a high rate of student learning as a result of the LWP. Their suggestion was that, in future years, each writing tutor provides feedback to the same group of students to more accurately monitor progress. This was implemented in 2016 and was well received, with regular reports from the writing tutors of student progress.

\section{CONCLUSION AND SUGGESTIONS FOR FURTHER RESEARCH}

The conclusion drawn is that legal thinking, reading and writing skills can only be acquired if they are explicated and developed in the context of their use. This means embedding them in law courses by scaffolding the texts and assignments of these courses and basing the literacy exercises on them. This integrated approach must be coupled with the explicit teaching of legal literacy skills and methods, as advocated by genre theory, and their implementation through active learning, as espoused by the academic literacies approach. This would encourage students to become critical thinkers and independent learners who question and evaluate texts, and in so doing construct their own knowledge rather than merely acquiring someone else's.

To achieve the goals and overcome the many challenges involved in the integration of literacy skills with disciplinary content, collaborative teaching between the disciplinary specialist and the writing instructor is suggested. By coupling the different skills of the two specialists, and their relative objectivity in relation to the law and its literacies, a productive partnership can emerge that best develops students' legal writing skills. Hopefully the lessons learnt from the LWP are useful enough to inform future legal writing interventions.

\section{REFERENCES}

BANGENI, B \& L GREENBAUM. 2013. An analysis of the textual practices of undergraduate and postgraduate novice writers in law. Per Linguam, 29(2):72-81.

BARTON, D \& M HAMILTON. 1998. Local literacies: Reading and writing in one community. London: Routledge.

BHATIA, VK. 1993. Analysing genre: Language use in professional settings. London: Longman.

BLOOM, E. 2008. A law school game changer: (Trans)formative feedback. Boston Legal Studies Research Paper Series Research Paper No. 14-08. Available from https://papers.ssrn.com/sol3/papers.cfm?abstract_id=2437060 [Accessed: 19 July 2018].

CALLAGHAN, M. \& J ROTHERY. 1988. Teaching factual writing: A genre-based Approach. Australia: Deacon University Press.

CALLEROS, CR. 2001. Using classroom demonstrations in familiar nonlegal contexts to introduce new students to unfamiliar concepts of legal method and analysis. Legal Writing Journal, 7:37-62.

CANDLIN, CN, VK BHATIA \& CH JENSEN. 2002. Developing legal writing materials for English second language learners: problems and perspectives. English for Specific Purposes, 21(4):299-320.

CLARENCE, S, L ALBERTUS \& L MWAMBENE. 2014. Building an evolving method and materials for teaching legal writing in large classes. Higher Education, 67(6):839-851.

OATES, L. 2006. Leveling the playing field: helping students succeed by helping them to read as expert lawyers. St. John's Law Review, 80:227-245. 
ELBOW, P. 1997. High stakes and low stakes in assigning and responding to writing. New Directions for Teaching and Learning, 69:5-13.

GEE, JP. 1991. Social linguistics: Ideology in discourses. London: Falmer.

GEE, JP. 1998. The New Literacy Studies: From 'socially situated' to the work of the social. Conference paper delivered at University of Lancaster, July 8-10, 1997. Available from http://jamespaulgee.com/pdfs/The\%20New\%20Literacy\%20Studies\%20and\%20the\%2 0Social\%20Turn.pdf (Accessed: 27 September, 2017).

GREENBAUM, L. 2004. Teaching legal writing at South African law faculties: A review of the current position and suggestions for the incorporation of a model based on new theoretical perspectives. Stellenbosch Law Review, 15(4):3-21.

HYLAND, K. 2000. Disciplinary discourses: Social interactions in academic writing. London: Longman.

JACOBS, C. 2005. On being an insider on the outside: New spaces for integrating academic literacies. Teaching in Higher Education, 10(4):475-487.

KRESS, G. 1985. Linguistic processes in sociocultural practices. Australia: Deacon University Press.

KRESS, G. 1993. Genre as social process. In B Cope \& M Kalantzis (Eds), The powers of literacy. Australia: Falmer. 22-37.

LEA, M \& B STREET. 1998. Student writing in higher education: An academic literacies approach. Studies in Higher Education, 23(2):257-173.

LEA, M. \& B STREET. 2006. The 'academic literacies' model: Theory and applications. Theory into Practice, 45(4):368-377.

LECLERQ, T. 1999. Principle 4: Good practice gives prompt feedback. Journal of Legal Education, 49(3):418-429.

LILLIS, T \& M SCOTT. 2007. Defining academic literacies research: Issues of epistemology, ideology and strategy. Journal of Applied Linguistics, 4(1):5-32.

LOUW, CH \& T BROODRYK. 2016. Teaching legal writing skills in the South African LLB curriculum: The role of the writing consultant. Stellenbosch Law Review, 27(3):535-553.

LUNDEBERG, MA. 1987 Metacognitive aspects of reading comprehension: Studying understanding in legal case analysis. Reading Research Quarterly, 22(4):407-432.

LYNCH, JA Jr. 2011. The new legal writing pedagogy: Is our pride and joy a hobble? Journal of Legal Education, 61:231-253.

MARTIN, JR. 1993. A contextual theory of language. In B Cope \& M Kalantzis (Eds), The Powers of Literacy. Australia: Falmer.

RIDEOUT, C \& J RAMSFIELD. 1994. Legal writing: A revised view. Washington Law Review, 69:75-94.

SAMUELSON, P. 1984. Good legal writing: Of Orwell and windowpanes. University of Pittsburgh Law Review, 46:149-163.

STREET, B. 1984. Literacy in theory and practice. Cambridge: Cambridge University Press.

STREET, B. 2003. What's 'new' in New Literacy Studies? Critical approaches to literacy in theory and practice. Current Issues in Comparative Education, 5(2):77-91.

SNYMAN-VAN DEVENTER, E \& N SWANEPOEL. 2013. Teaching South African law students (legal) writing skills. Stellenbosch Law Review, 24(3):511-527.

SWANEPOEL, N \& E SNYMAN-VAN DEVENTER. 2012. The need for a legal-writing course in the South African LLB curriculum. Obiter, 33(1):121-134.

THE NEW LONDON GROUP: Cazden, C, B Cope, N Fairclough \& J Gee. 1996. A pedagogy of multiliteracies: Designing social futures. Harvard Educational Review, 66(1):61-83.

VENTER, C. 2006. Analyze this: Using taxonomies to 'scaffold' students' legal thinking and writing skills. Mercer Law Review, 57:631-645. 
WICKERT, R \& M BAYNHAM. 1994. Just like farmland and goldmines: Workplace literacies in an era of long-term unemployment. In Literacies and the work place: A collection of original essays. Available from http://files.eric.ed.gov/fulltext/ED384707.pdf [Accessed: 27 September 2017].

\section{BIOGRAPHICAL NOTES}

Toni Gottlieb has taught legal writing to first-year Law students at the University of Cape Town, to pupils at the Johannesburg Bar, and to Candidate Attorneys at Bowmans law firm in Cape Town. She has also taught English for Academic and Specific Purposes at the University of Johannesburg.

Lesley Greenbaum is an Associate Professor in the Department of Private Law at UCT. Her research interests are legal education, the law curriculum and legal writing. She is the convenor of the Legal Writing Project for first year law students. 